\title{
Sphincterotomy with endoscopic biliary drainage for severe acute cholangitis: a meta-analysis
}

\section{(ㅇ)( $\odot$}

Authors

Tarek Sawas ${ }^{1}$, Noura Arwani ${ }^{1}$, Shadi Al Halabi², John Vargo ${ }^{3}$

Institutions

1 Department of Gastroenterology and Hepatology, Mayo Clinic, Rochester, Minnesota, USA

2 Department of Internal Medicine, Cleveland Clinic, Cleveland, Ohio, USA

3 Department of Gastroenterology and Hepatology, Digestive Disease and Surgery Institute, Cleveland Clinic, Cleveland, Ohio, USA

submitted 21.1.2016

accepted after revision 4.10 .2016

Bibliography

DOI http://dx.doi.org/10.1055/s-0042-120412 |

Endoscopy International Open 2017; 05: EE103-EE109

(c) Georg Thieme Verlag KG Stuttgart · New York

ISSN 2364-3722

Corresponding author

Tarek Sawas, MD, Mayo Clinic, 216 2nd St SW, Rochester, MN

55902, USA

Fax: +1-507-255-7612

tareksawas@yahoo.com

\section{ABSTRACT}

Aims To investigate the role of endoscopic sphincterotomy (ES) with endoscopic biliary drainage (EBD) in acute severe obstructive cholangitis management by performing a meta-analysis of controlled trials.

Method We searched PubMed and Embase for controlled studies that compared endoscopic drainage with ES versus Non-ES in acute obstructive cholangitis. Two reviewers selected the studies and extracted the data. Disagreement was addressed by a third reviewer. Heterogeneity of the studies was analyzed by Cochran's Q statistics. A Mantel-Haenszel risk ratio was calculated utilizing a random effects model.

Results Four controlled studies met our inclusion criteria with 392 participants (201 ES, 191 Non-ES). The outcomes were drainage insertion success rate, drainage effectiveness, post drainage pancreatitis, bleeding, procedure duration, perforation, cholecystitis, and 30-day mortality. Drainage insertion success rate was identical in both groups (RR: $1.00,95 \% \mathrm{Cl} \% 0.96-1.04)$. Effective drainage was not significantly different (RR: $1.11,95 \% \mathrm{Cl} 0.73-1.7)$. There was no significant difference in the incidence of pancreatitis post EBD between the ES and Non-ES groups at $3 \%$ and $4 \%$, respectively (RR: $0.73,95 \% \mathrm{Cl} 0.24-2.27)$. However, there was a significant increase in post EBD bleeding with ES compared to Non-ES (RR: $8.58,95 \% \mathrm{Cl}$ 2.03 - 36.34). Thirty-day mortality was similar between ES and NonES groups at $0.7 \%$ and $1 \%$, respectively (RR: $0.5,95 \% \mathrm{Cl} 0.05-5.28$ ). Conclusion Our findings show that EBD without ES is an effective drainage technique and carries less risk for post procedure bleeding. Patients who are critically ill and have coagulopathy should be spared from undergoing ES in the acute phase.

\section{Introduction}

Acute cholangitis is a serious medical condition that requires immediate drainage to relieve the obstruction and prevent complications. Biliary obstruction is usually caused by choledocholithiasis, or by a benign or malignant biliary stricture [1]. Emergent surgery in acute cholangitis is associated with a significant mortality rate $(20-40 \%)$ [2,3]. Endoscopic biliary drainage (EBD) is the standard of care with high success rates and low morbidity [3]. Endoscopic sphincterotomy (ES) is usually a safe procedure which is done to facilitate cannulation, bile duct stone removal, and biliary drainage [4, 5]. However, the role of ES in severe acute cholangitis is controversial and may not always be feasible because of the severity of illness and the risk of significant bleeding [6]. The aim of the current meta-analysis is to investigate the role of ES with EBD in severe acute obstructive cholangitis by performing a meta-analysis of controlled trials.

\section{Methods}

\section{Search strategy and study selection}

A search routine was developed to identify all human studies that assessed sphincterotomy with endoscopic biliary drainage in severe acute cholangitis published in PubMed and Embase up to March 2015. The following search terms were used: sphincterotomy, biliary drainage, biliary stent, suppurative cholangitis, acute cholangitis, and cholangitis. Reference lists of relevant original papers, review articles and guidelines were examined. There was no language or date restriction. Reports without original data (meta-analysis, review, editorial, letter, comment, news, guidelines), animal, and in vitro studies were excluded. We also excluded studies that evaluated sphincterotomy for other indications. Thus, studies were included in the systematic review and meta-analysis if they were controlled studies that compared sphincterotomy with biliary drainage to biliary drainage alone without sphincterotomy in severe acute cholangitis. 


\section{Outcome assessment}

The outcomes were the drainage insertion success rate, drainage effectiveness, post drainage pancreatitis, bleeding, procedure duration, perforation, cholecystitis, and 30-day mortality.

Acute cholangitis diagnosis was made by two criteria: (1) clinical symptoms of abdominal infection including fever, leukocytosis, and abdominal pain, (2) signs of biliary obstruction such as jaundice, hyperbilirubinemia, and biliary dilatation on ultrasound or computed tomography (CT). Severe cholangitis was defined as cholangitis with one of the following: shock, altered mental status, high fever $>39^{\circ} \mathrm{C}$, end organ failure, clinical evidence of peritoneal inflammation, or evidence of purulent bile [7].

Drainage effectiveness was defined as a reduction in serum bilirubin $>50 \%$ of baseline level at 1 week and disappearance of all signs of cholangitis. EBD was considered emergent when performed within 24 hours and urgent when performed within 72 hours [8]. Post-sphincterotomy hemorrhage was divided into immediate and delayed. Immediate hemorrhage was considered when there was endoscopic evidence of bleeding that forced abandonment of the procedure. Delayed hemorrhage was defined by clinical evidence of melena or hematemesis with a decrease in hemoglobin $(\mathrm{Hb})$ of more than $2 \mathrm{~g} / \mathrm{dL}$, or the need for blood transfusion. We combined both types of bleeding under one outcome.

\section{Data extraction}

Two investigators (TS, NA) independently reviewed identified abstracts and selected papers for full review. Discrepancies were resolved by a third reviewer (SA). For each selected publication, key study characteristics were abstracted including publication year, country, study design, participant characteristics (age, gender), biliary drainage method, the underlying cause of acute cholangitis, successful drainage placement, effective drainage, post drainage incidence of acute pancreatitis or bleeding, procedure duration, and death. We followed the Preferred Reporting Items for Systematic Reviews and MetaAnalyses (PRISMA) [9] Statement guidelines for the current meta-analysis.

\section{Assessment of risk of bias}

The risk of bias of included studies was assessed using domainbased risk of bias tables, as recommended by the Cochrane Collaboration (http://handbook.cochrane.org) (March 2011). Each study was assessed independently across different areas of potential bias, namely study participation, allocation, randomization, blinding of participants and outcome, study attrition, and reporting. The overall risk of bias for an individual study is categorized as low (if the risk of bias is low in all domains), high (if the risk of bias is high in at least one domain), or unclear (if the risk of bias is unclear in at least one domain, and no domains have a high or moderate risk of bias).

\section{Statistical methods}

The intention-to-treat numbers were extracted from the included studies for the desired outcomes. The results were

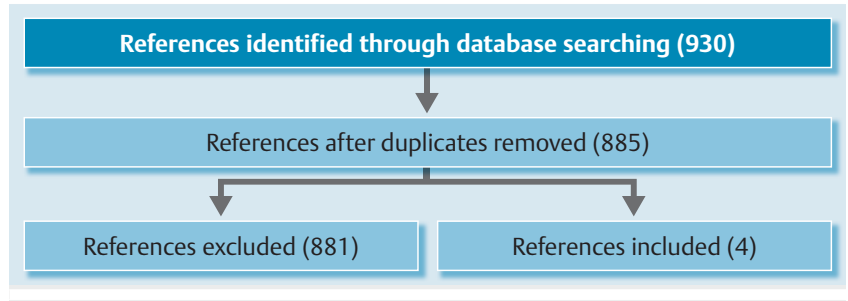

Fig. 1 Flowchart of the systematic review and meta-analysis.

presented as risk ratio for dichotomous outcome measures with $95 \%$ confidence intervals $(95 \% \mathrm{Cl})$ and mean difference for continuous outcomes with $95 \% \mathrm{Cl}$. Outcomes from individual studies were combined with the random effects model. Repeat analysis was performed using a fixed effects model in the sensitivity analysis. Heterogeneity among studies was assessed with the inconsistency index $\left(\mathrm{I}^{2}\right)$ statistic, which ranges from $0 \%$ to $100 \%$ and is defined as the percentage of the observed intertrial variability that is due to heterogeneity rather than chance for each outcome $\left(\mathrm{I}^{2}>50 \%\right.$ denotes significant heterogeneity). Statistical heterogeneity was examined by sensitivity analyses to clarify if any clinical heterogeneity was responsible for such statistical difference. All statistical analyses were performed using RevMan software version 5.2 (Review Manager, Copenhagen, Denmark: The Nordic Cochrane Center, The Cochrane Collaboration 2012) where two-tailed $P$ values $<0.05$ were considered significant.

\section{Results}

\section{Study characteristics and methodologies}

Our search yielded 885 references after removal of duplicates. Of those, only four studies [8, 10 - 12] met our inclusion criteria for the systematic review and meta-analysis with 392 participants (201 ES, 191 Non-ES) ( Fig. 1). All four studies were conducted in Asia with a mean age of 69.

Three out of the four studies were retrospective controlled trials $[8,10,12]$ and one study was a randomized controlled trial (RCT) [11]. All four studies were high risk for bias for certain bias items ( Supplementary Fig. 1).

All patients were treated with supportive fluid and antibiotics before the endoscopic intervention. Biliary drainage method varied between nasobiliary drainage in two studies $[8,11]$, plastic stents only in one study [10], and either of these methods in one study [12] ( Table 1). Both Hui et al. [10] and Park et al. [12] used 6-7 Fr plastic stents. Biliary drainage was performed in all patients in both groups in three studies $[8,10$, 11] even if sphincterotomy was performed. Park et al. [12] performed biliary drainage in all patients in the non-ES group but only in patients with remnant stones or a high suspicion of remnant stones in the ES group. The timing for the biliary drainage was emergent (within 24 hours) in three studies [10-12] and urgent in one study [8]. Choledocholithiasis was the major cause of acute cholangitis in all studies. Another cause was benign biliary strictures. Only Sugiyama and Atomi [8] included patients with malignant biliary obstruction as the underlying 
cause of the acute cholangitis ( $>$ Table 1 ). Hui et al. [10] and Zhang et al. [11] excluded patients with coagulopathy. Sugiyama and Atomi [8] did not exclude patients with coagulopathy but there was no significant difference between the ES group and the non-ES at $8 \%$ and $13 \%$, respectively. No subgroup analysis was performed. Park et al. [12] also included patients with coagulopathy only in the non-ES group. Hui et al. performed second endoscopic retrograde cholangiopancreatography (ERCP) in all patients 4 to 8 weeks later for bile duct stone removal. All patients in Zhang et al. [11] underwent a second elective ERCP or surgery for bile duct stone removal. Both Sugiyama and Atomi [8] and Park et al. [12] did not mention a second ERCP or surgical intervention.

\section{Outcomes}

\section{Drainage insertion success rate}

Drainage insertion success rate was evaluated in three studies. Sugiyama and Atomi [8] reported four drainage failures in the ES group and four in the Non-ES group. Failures in the ES group were attributed to unsuccessful sphincterotomy (2 patients), severe stricture (1 patient), and long malignant stricture (1 patient). Those failed cases were managed with percutaneous transhepatic biliary drainage (PTBD). Drainage failure in the Non-ES group was attributed to difficult deep cannulation (2 patients), which was managed by performing ES, and long malignant stricture (2 patients), which was managed with PTBD. Hui et al. [10] reported nine failed cases (5 Non-ES, 4 ES). They were all managed with PTBD. All drainage insertions were successful in the study by Zhang et al. [11]. Overall drainage insertion success rate was the same in both groups (RR: $1.00,95 \% \mathrm{Cl}$ $0.96-1.04)$ with no significant heterogeneity $\left(I^{2}: 0 \%\right)$ ( Fig. 2 ).

\section{Drainage effectiveness}

Two studies reported this outcome ( $>$ Table 2 ). There was no significant difference between ES and Non-ES groups (RR: $1.11,95 \% \mathrm{Cl} 0.73-1.7)$. Significant heterogeneity was noted $\left(I^{2}: 73 \%\right)$ ( Supplementary Fig. 2).

\section{Post drainage acute pancreatitis}

Acute pancreatitis was reported in all four studies [8, 10-12] ( $\downarrow$ Table 2 ). Acute pancreatitis occurred in $3 \%$ of patients in the sphincterotomy group compared to $4 \%$ in the Non-ES group (RR: $0.73,95 \% \mathrm{Cl} 0.24-2.27$ ) with no significant heterogeneity (I2: $0 \%)$ ( Fig. $\mathbf{3}$ ).

\section{Post drainage hemorrhage}

All four included studies reported this outcome [8, 10-12]. Patients who underwent sphincterotomy had significantly greater risk for post drainage hemorrhage (RR: 8.58, 95\%Cl $2.03-$ 36.34) with no significant heterogeneity (I2: $0 \%)$ ( Fig. 4).

\section{Procedure duration}

Two studies reported procedure duration $[10,11]$. The duration of the procedure was significantly shorter in the Non-ES group compared to the ES group (Mean Difference: 3.61 min- utes, $95 \% \mathrm{Cl} 2.79-4.42)$ without significant heterogeneity ( $\mathrm{I}^{2}$ : $0 \%$ ) ( Supplementary Fig.3).

\section{Perforation}

Perforation included retroperitoneal or bowel-wall perforation as evidenced by any imaging technique. Three studies reported this outcome $[8,10,11]$. No perforations were reported in either group.

\section{Cholecystitis}

Only Sugiyama and Atomi [8] reported cholecystitis after biliary drainage. Cholecystitis complicated 3/73 in the ES group. No one developed cholecystitis in the non-ES group and the difference was statistically significant $(P<0.05)$.

\section{Thirty-day mortality}

Hui et al. [10] reported three deaths. In the ES group, one patient died from septic shock, and in the non-ES group, two patients died because of multi-organ failure. Park et al. [12] reported one death secondary to cardiogenic shock in a patient with recent myocardial infarction. Neither Sugiyama and Atomi [8] nor Zhang et al. [11] reported any deaths in either group. Overall mortality rate was $0.5 \%$ in the ES and $1 \%$ in the Non-ES group (RR: $0.5,95 \% \mathrm{Cl} 0.05-5.28$ ) without significant heterogeneity $\left(I^{2}: 0 \%\right)$.

\section{Sensitivity analysis}

We performed a sensitivity analysis in which we removed one study at a time. We also changed the analysis method from random effects to a fixed effects model. The sensitivity analyses did not change the direction or the significance of any of the RRs or the level of heterogeneity in any of the analyses. Using a fixed effects model, differences in insertion success rate, drainage effectiveness, and post ERCP pancreatitis remained insignificant at RR: $1(95 \% \mathrm{Cl} 0.95-1.06)$, RR: $1.05(95 \% \mathrm{Cl}$ $0.94-1.17)$, and RR: $0.75(95 \% \mathrm{Cl} 0.26-2.2)$, respectively. The difference in post ERCP hemorrhage remained significant (RR: $8.62,95 \% \mathrm{Cl} 2.02-36.72$ ). The numbers remained exactly the same for procedure duration and 30-day mortality.

We also divided the studies into two groups according to the drainage method used: nasobiliary drain (NBD) [8, 11,12] or biliary stenting $[10,12]$. In the NBD group, the results remained the same. There was no significant difference between ES and Non-ES groups in the insertion success rate (RR: $1,95 \% \mathrm{Cl}$ $0.95-1.04$ ) or effective drainage (RR: $1.11,95 \% \mathrm{Cl} 0.73-$ 1.70). The incidence of post ERCP pancreatitis was not significantly different (RR: $0.53,95 \% \mathrm{Cl} 0.14-2.00$ ). Hemorrhage was significantly lower in the Non-ES group (RR: $9.16,95 \% \mathrm{Cl}$ 1.75-48.11). Data were limited in the biliary stent group and we could not perform a subgroup analysis.

\section{Discussion}

Severe acute cholangitis is a medical emergency that carries significant morbidity and mortality if not treated promptly. Besides medical management with supportive fluid and antibiotics, adequate biliary drainage is essential. Historically, patients 


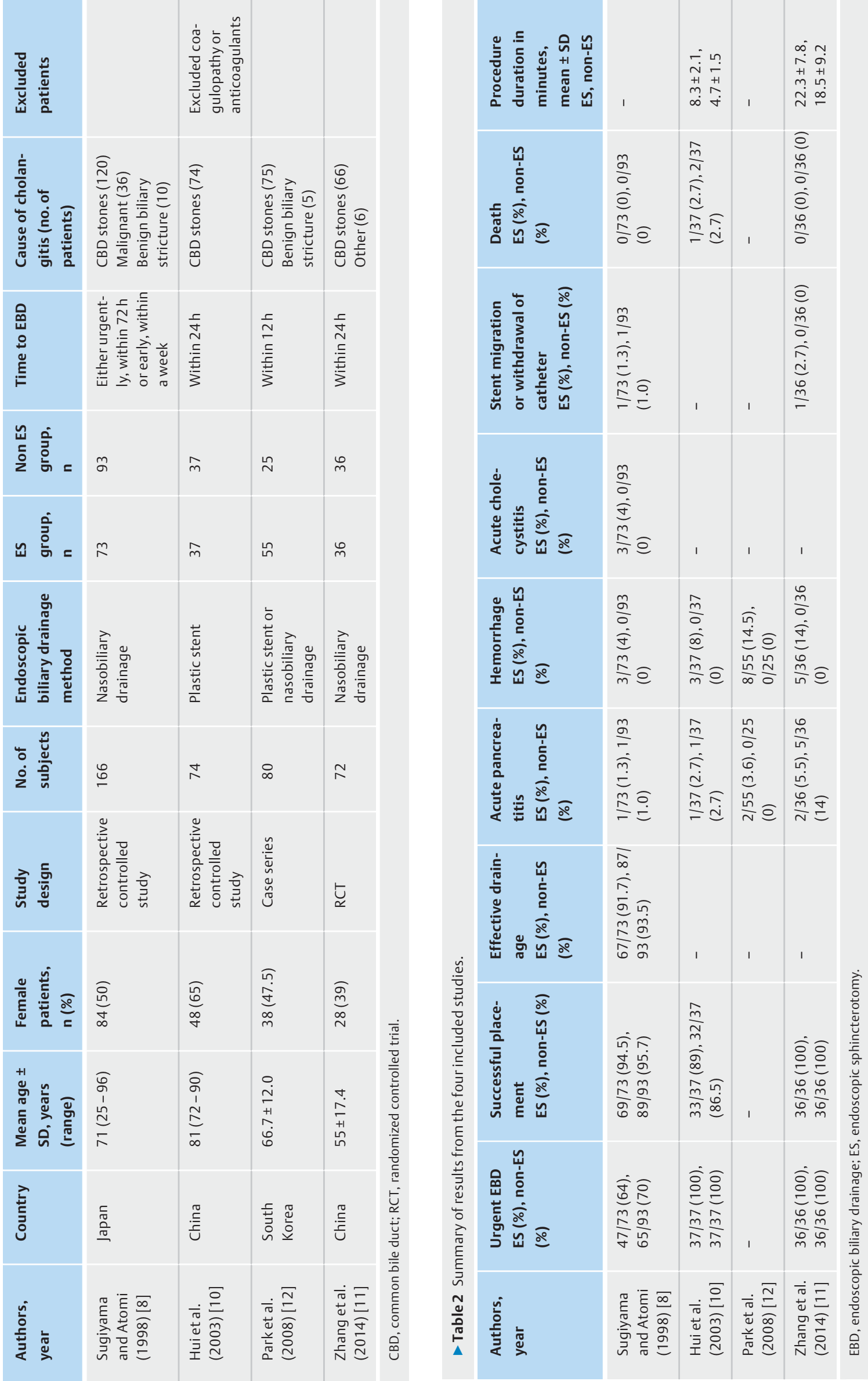




\begin{tabular}{|c|c|c|c|c|c|c|c|c|}
\hline \multirow[b]{2}{*}{ Study or Subgroup } & \multicolumn{2}{|c|}{ Sphincterotomy } & \multicolumn{2}{|c|}{ No sphincterotomy } & \multirow[b]{2}{*}{ Weight } & \multirow{2}{*}{$\begin{array}{c}\text { Risk Ratio } \\
\text { M-H, Random, } 95 \% \mathrm{CI}\end{array}$} & \multirow{2}{*}{$\begin{array}{c}\text { Risk Ratio } \\
\text { M-H, Random, } 95 \% \mathrm{Cl}\end{array}$} & \\
\hline & Events & Total & Events & Total & & & & \\
\hline Hui 2003 & 33 & 37 & 32 & 37 & $5.9 \%$ & $1.03[0.87,1.22]$ & $\longrightarrow$ & \\
\hline Sugiyama 1998 & 69 & 73 & 89 & 93 & $34.5 \%$ & $0.99[0.92,1.06]$ & $\rightarrow-$ & \\
\hline Zhang 2014 & 36 & 36 & 36 & 36 & $59.6 \%$ & $1.00[0.95,1.05]$ & - & \\
\hline Total $(95 \% \mathrm{Cl})$ & & 146 & & 166 & $100.0 \%$ & $1.00[0.96,1.04]$ & & \\
\hline Total events & 138 & & 157 & & & & & \\
\hline \multicolumn{5}{|c|}{ Heterogeneity: $\operatorname{Tau}^{2}=0.00 ; \mathrm{Chi}^{2}=0.25, \mathrm{df}=2(\mathrm{P}=0.88) ; \mathrm{I}^{2}=0 \%$} & & 0.5 & $\begin{array}{ll}0.7 & 1\end{array}$ & 1.5 \\
\hline \multicolumn{5}{|c|}{ Test for overall effect: $Z=0.12(P=0.91)$} & & Favours no & sphincterotomy Favours sph & incterotomy \\
\hline
\end{tabular}

- Fig. 2 Forest plot, meta-analysis of controlled trials comparing biliary drainage with sphincterotomy to no sphincterotomy, risk ratio and $95 \%$ confidence interval for drainage insertion success rate.

\begin{tabular}{|c|c|c|c|c|c|c|c|c|}
\hline \multirow[b]{2}{*}{ Study or Subgroup } & \multicolumn{2}{|c|}{ Sphincterotomy } & \multicolumn{2}{|c|}{ No sphincterotomy } & \multirow[b]{2}{*}{ Weight } & \multirow{2}{*}{$\begin{array}{c}\text { Risk Ratio } \\
\text { M-H, Random, } 95 \% \mathrm{CI}\end{array}$} & \multirow{2}{*}{\multicolumn{2}{|c|}{$\begin{array}{c}\text { Risk Ratio } \\
\text { M-H, Random, } 95 \% \mathrm{Cl}\end{array}$}} \\
\hline & Events & Total & Events & Total & & & & \\
\hline Hui 2003 & 1 & 37 & 1 & 37 & $17.1 \%$ & $1.00[0.06,15.40]$ & & \\
\hline Park 2008 & 2 & 55 & 0 & 25 & $14.2 \%$ & $2.32[0.12,46.65]$ & & $\longrightarrow$ \\
\hline Sugiyama 1998 & 1 & 73 & 1 & 93 & $16.9 \%$ & $1.27[0.08,20.02]$ & & $=$ \\
\hline Zhang 2014 & 2 & 36 & 5 & 36 & $51.8 \%$ & $0.40[0.08,1.93]$ & 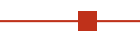 & - \\
\hline Total $(95 \% \mathrm{Cl})$ & & 201 & & 191 & $100.0 \%$ & $0.73[0.24,2.27]$ & & \\
\hline Total events & 6 & & 7 & & & & & \\
\hline \multicolumn{5}{|c|}{ Heterogeneity: $\mathrm{Tau}^{2}=0.00 ; \mathrm{Chi}^{2}=1.34, \mathrm{df}=3(\mathrm{P}=0.72) ; \mathrm{I}^{2}=0 \%$} & & 0.01 & 1 & 10 \\
\hline \multicolumn{5}{|c|}{ Test for overall effect: $Z=0.54(P=0.59)$} & & Favours spl & incterotomy & Favours no sph \\
\hline
\end{tabular}

- Fig. 3 Forest plot, meta-analysis of controlled trials comparing biliary drainage with sphincterotomy to no sphincterotomy, risk ratio and $95 \%$ confidence interval for post drainage acute pancreatitis

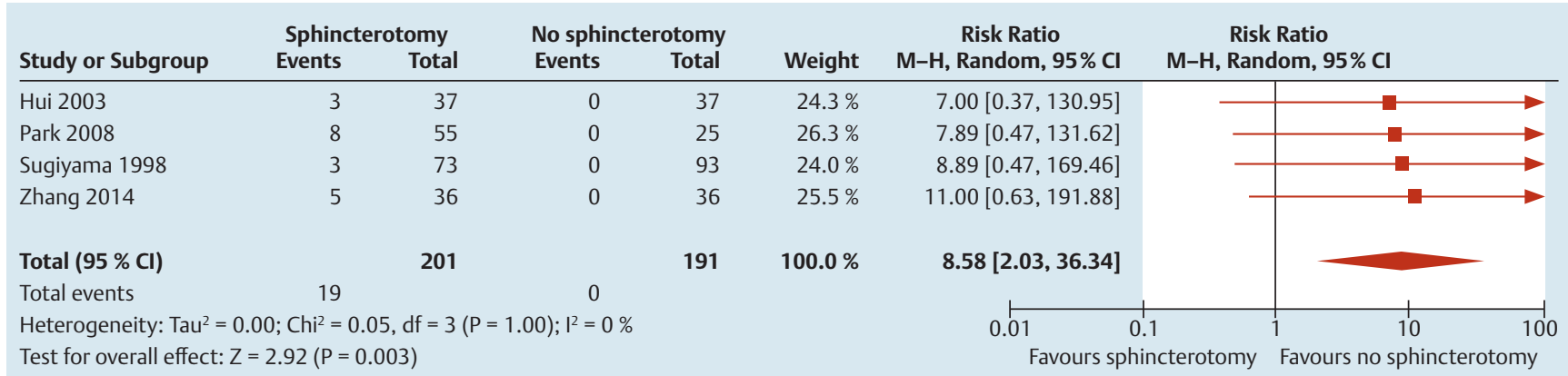

Fig. 4 Forest plot, meta-analysis of controlled trials comparing biliary drainage with sphincterotomy to no sphincterotomy, risk ratio and $95 \%$ confidence interval for post drainage hemorrhage

with severe obstructive cholangitis underwent surgical drainage. However, this approach was associated with significant complications and a high mortality rate [2]. Endoscopic biliary drainage with ERCP has provided a safe noninvasive method of drainage $[13,14]$ for severe acute cholangitis with a lower mortality risk [3]. Biliary drainage is performed by either endoscopic nasobiliary drainage (NBD) or endoscopic biliary stenting. The drainage is usually performed in association with sphincterotomy and stone extraction as the treatment of choice for choledocholithiasis [15-17]. However, patients with severe acute cholangitis and sepsis are at risk for coagulopathy and bleeding which makes ES a high risk procedure. It was proposed that biliary drainage should be performed without sphincterotomy in severe acute cholangitis $[8,15]$.
This meta-analysis included four experimental controlled trials with 392 participants. Our results showed that endoscopic biliary drainage (EBD) without sphincterotomy in severe acute cholangitis is as effective as biliary drainage with sphincterotomy in achieving adequate biliary drainage. Performing EBD without ES significantly decreased the risk of bleeding (relative risk reduction RRR: $100 \%$ ). The incidence of post ES bleeding was $10 \%$, which is similar to the reported incidence in the literature $(0-12 \%)[3,15]$. Theoretically, the concern about performing EBD without ES is the development of acute pancreatitis from pancreatic duct blockage. However, our meta-analysis showed no significant difference in the incidence of post ERCP pancreatitis. The duration of the procedure was significantly shorter in the Non-ES group compared to the ES group (Mean Difference: 3.61 minutes, $P<0.001$ ). This is an im- 
portant point in critically ill patients in whom sedation may carry a higher risk and may worsen hemodynamic instability. Mortality rate was low in both groups. No perforation was reported in any of the studies.

The majority of patients (279) in the included studies were treated with nasobiliary drainage. One limitation of NBD is the frequent removal of the catheter by patients which subsequently compromises drainage [17]. The incidence of NBD catheter withdrawal in our meta-analysis was only $1 \%$. Park et al. [12] compared NBD to biliary stenting in severe acute cholangitis in 80 patients. Both methods were equally effective in obtaining adequate biliary drainage and resolving symptoms of acute cholangitis. Another randomized controlled trial by Sharma et al. [18] concluded that biliary drainage with NBD or biliary stenting are equally safe and effective in severe acute cholangitis. NBD has several advantages: (1) it facilitates follow-up cholangiography; (2) it allows follow-up bile cultures; 3 ) its patency can be maintained by lavage $[12,18]$. However, the catheters are at risk of being kinked or pulled out by confused patients. They are also associated with significant discomfort. These problems are not encountered with stents. In addition, stents have the advantage of providing physiologic internal drainage, which restores both fluid and electrolyte balance and the equilibrium of the bacterial flora [18]. The complications of stenting are occlusion and migration. Stents are recommended when there is concern about drainage removal by confused patients.

To our knowledge, this is the first meta-analysis evaluating the role of sphincterotomy in severe acute cholangitis. Cui et al. [19] investigated the benefit of ES in malignant biliary obstruction in a meta-analysis of three RCTs (338 participants). There was no significant difference in stent insertion success rate between the two groups but the incidence of post ERCP bleeding was significantly higher in the ES group, similar to our meta-analysis.

This analysis had the following limitations: (1) We included retrospective controlled studies. (2) The low number of included studies (four studies) and the fact that they were all performed in Asia may limit generalizability. (3) We combined NBD and biliary stenting under one group. However, we based our approach on studies which showed that NBD and biliary stenting are equally safe and effective in severe acute cholangitis $[12,18]$. (4) We were not able to provide data with regard to the decrease in bilirubin level, liver enzymes, and white blood cells since only one study reported these outcomes [11]. A large randomized controlled trial is needed to determine their effect on mortality.

Our findings show that EBD with and without ES are equally effective drainage techniques in severe acute cholangitis. EBD without ES carries fewer risks for post ERP bleeding. Patients who are critically ill and have coagulopathy should be spared from undergoing ES in the acute phase.
Competing interests

None

References

[1] Sawas T, Al Halabi S, Parsi MA et al. Self-expandable metal stents versus plastic stents for malignant biliary obstruction: a meta-analysis. Gastrointest Endosc 2015; 82: 256-267.e7

[2] Lai EC, Tam PC, Paterson IA et al. Emergency surgery for severe acute cholangitis. The high-risk patients. Ann Surg 1990; 211: 55-59

[3] Lai EC, Mok FP, Tan ES et al. Endoscopic biliary drainage for severe acute cholangitis. NEJM 1992; 326: $1582-1586$

[4] Kawai K, Akasaka Y, Murakami K et al. Endoscopic sphincterotomy of the ampulla of Vater. Gastrointest Endosc 1974; 20: 148-151

[5] Weber A, Roesch T, Pointner S et al. Transpancreatic precut sphincterotomy for cannulation of inaccessible common bile duct: a safe and successful technique. Pancreas 2008; 36: 187-191

[6] Freeman ML, Nelson DB, Sherman S et al. Complications of endoscopic biliary sphincterotomy. NEJM 1996; 335: 909-918

[7] Wada K, Takada T, Kawarada Y et al. Diagnostic criteria and severity assessment of acute cholangitis: Tokyo Guidelines. J Hepatobiliary Pancreat Surg 2007; 14: $52-58$

[8] Sugiyama M, Atomi Y. The benefits of endoscopic nasobiliary drainage without sphincterotomy for acute cholangitis. Am J Gastroenterol 1998; 93: $2065-2068$

[9] Liberati A, Altman DG, Tetzlaff ] et al. The PRISMA statement for reporting systematic reviews and meta-analyses of studies that evaluate health care interventions: explanation and elaboration. J Clin Epidemiol 2009; 62: e1-34

[10] Hui CK, Lai KC, Yuen MF et al. Does the addition of endoscopic sphincterotomy to stent insertion improve drainage of the bile duct in acute suppurative cholangitis? Gastrointest Endosc 2003; 58: 500 504

[11] Zhang RL, Zhao H, Dai YM et al. Endoscopic nasobiliary drainage with sphincterotomy in acute obstructive cholangitis: a prospective randomized controlled trial. J Dig Dis 2014; 15: 78 - 84

[12] Park SY, Park CH, Cho SB et al. The safety and effectiveness of endoscopic biliary decompression by plastic stent placement in acute suppurative cholangitis compared with nasobiliary drainage. Gastrointest Endosc 2008; 68: 1076-1080

[13] Leung JW, Chung SC, Sung JJ et al. Urgent endoscopic drainage for acute suppurative cholangitis. Lancet 1989; 1: 1307-1309

[14] Lee JG. Diagnosis and management of acute cholangitis. Nat Rev Gastroenterol Hepatol 2009; 6: 533-541

[15] Boender J, Nix GA, de Ridder MA et al. Endoscopic sphincterotomy and biliary drainage in patients with cholangitis due to common bile duct stones. Am J Gastroenterol 1995; 90: 233-238

[16] Committee ASoP. Maple JT, Ben-Menachem T et al. The role of endoscopy in the evaluation of suspected choledocholithiasis. Gastrointest Endosc 2010; 71: 1 -9

[17] Kiil ], Kruse A, Rokkjaer M. Large bile duct stones treated by endoscopic biliary drainage. Surgery 1989; 105: $51-56$

[18] Sharma BC, Kumar R, Agarwal N et al. Endoscopic biliary drainage by nasobiliary drain or by stent placement in patients with acute cholangitis. Endoscopy 2005; 37: 439-443

[19] Cui PJ, Yao J, Zhao Y] et al. Biliary stenting with or without sphincterotomy for malignant biliary obstruction: a meta-analysis. World J Gastroenterol 2014; 20: 14033-14039 


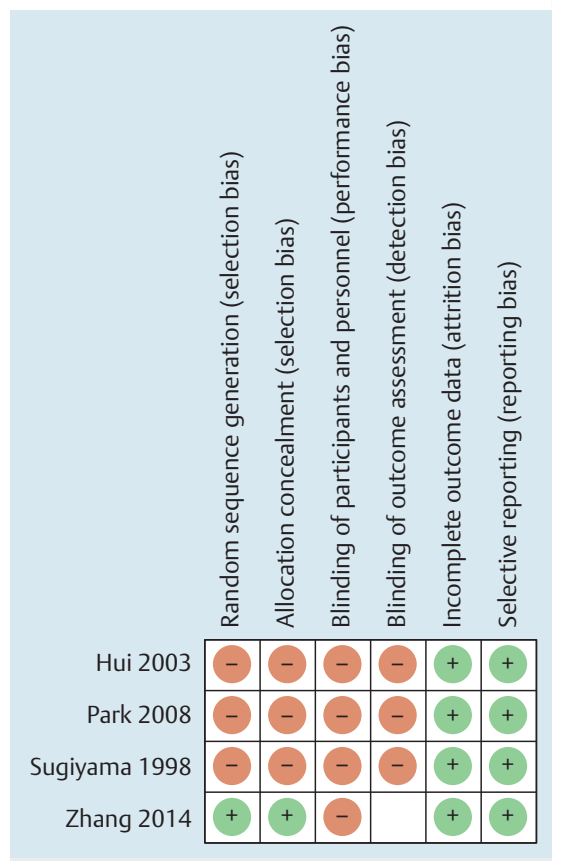

- Supplementary Fig. 1 Risk of bias summary: authors' judgments about each risk of bias item for each included study. Green, low risk for bias; red, high risk for bias.

\begin{tabular}{|c|c|c|c|c|c|c|c|c|c|}
\hline Study or Subgroup & \multicolumn{2}{|c|}{ Sphincterotomy } & \multicolumn{2}{|c|}{ No sphincterotomy } & Weight & $\begin{array}{c}\text { Risk Ratio } \\
\text { M-H, Random, } 95 \% \mathrm{CI}\end{array}$ & Year & $\begin{array}{c}\text { Risk Ratio } \\
\text { M-H, Random, 95\% CI }\end{array}$ & \\
\hline Sugiyama 1998 & 67 & 73 & 87 & 93 & $62.6 \%$ & $0.98[0.90,1.07]$ & 1998 & 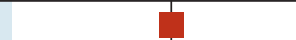 & \\
\hline Zhang 2014 & 22 & 36 & 16 & 36 & $37.4 \%$ & $1.38[0.88,2.15]$ & 2014 & $t$ & \\
\hline Total $(95 \% \mathrm{Cl})$ & & 109 & & 129 & $100.0 \%$ & $1.11[0.73,1.70]$ & & 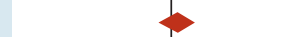 & \\
\hline Total events & 89 & & 103 & & & & & & \\
\hline \multicolumn{5}{|c|}{ Heterogeneity: $\operatorname{Tau}^{2}=0.07 ; \mathrm{Chi}^{2}=3.68, \mathrm{df}=1(\mathrm{P}=0.05) ; \mathrm{I}^{2}=73 \%$} & \multirow{2}{*}{\multicolumn{5}{|c|}{$\begin{array}{ccccc}0.02 & 0.1 & 1 & 10 & 50 \\
\text { Favours no sphincterotomy } & \text { Favours sphincterotomy }\end{array}$}} \\
\hline \multicolumn{5}{|c|}{ Test for overall effect: $Z=0.49(P=0.62)$} & & & & & \\
\hline
\end{tabular}

- Supplementary Fig. 2 Forest plot, meta-analysis of controlled trials comparing biliary drainage with sphincterotomy to no sphincterotomy, risk ratio and $95 \%$ confidence interval for drainage effectiveness.

\begin{tabular}{|c|c|c|c|c|c|c|c|c|c|c|c|c|}
\hline \multirow{2}{*}{$\frac{\text { Study or Subgroup }}{\text { Hui } 2003}$} & \multicolumn{3}{|c|}{ Sphincterotomy } & \multicolumn{3}{|c|}{ No sphincterotomy } & \multirow{2}{*}{$\begin{array}{r}\text { Weight } \\
95.7 \%\end{array}$} & \multirow{2}{*}{$\begin{array}{c}\begin{array}{c}\text { Mean Difference } \\
\text { IV, Random, 95\% CI }\end{array} \\
3.60[2.77,4.43]\end{array}$} & \multirow{2}{*}{$\begin{array}{r}\text { Year } \\
2003\end{array}$} & \multicolumn{2}{|c|}{$\begin{array}{c}\text { Mean Difference } \\
\text { IV, Random, } 95 \% \mathrm{CI}\end{array}$} & \\
\hline & 8.3 & 2.1 & 37 & 4.7 & 1.5 & 37 & & & & & & \\
\hline Zhang 2014 & 22.3 & 7.8 & 36 & 18.5 & 9.2 & 36 & $4.3 \%$ & $3.80[-0.14,7.74]$ & 2014 & & & \\
\hline Total $(95 \% \mathrm{Cl})$ & & & 73 & & & 73 & $100.0 \%$ & $3.61[2.79,4.42]$ & & & $\rightarrow$ & \\
\hline Total events & 89 & & & 103 & & & & & & & & \\
\hline \multicolumn{7}{|c|}{ Heterogeneity: $\operatorname{Tau}^{2}=0.00 ; \mathrm{Chi}^{2}=0.01, \mathrm{df}=1(\mathrm{P}=0.92) ; \mathrm{I}^{2}=0 \%$} & & & & $10-5$ & 0 & $\begin{array}{ll}1 & 10 \\
5 & 10\end{array}$ \\
\hline \multicolumn{7}{|c|}{ Test for overall effect: $Z=8.69(P<0.00001)$} & & & Favours & 5 sphincterotomy & Favours no & sphincterotomy \\
\hline
\end{tabular}

Supplementary Fig. 3 Forest plot, meta-analysis of controlled trials comparing biliary drainage with sphincterotomy to no sphincterotomy, mean difference and $95 \%$ confidence interval for procedure duration in minutes. 